\title{
Large-scale high-temperature solar energy storage using natural natural minerals
}

Monica Benitez-Guerrero ${ }^{1,2}$, Beatriz Sarrion ${ }^{2}$, Antonio Perejon ${ }^{2,} 3$, Pedro E. SanchezJimenez $^{2}$, Luis A. Perez-Maqueda ${ }^{2}$, Jose Manuel Valverde ${ }^{1 *}$

${ }^{1}$ Facultad de Física, Universidad de Sevilla, Avenida Reina Mercedes s/n, 41012 Sevilla, Spain.

${ }^{2}$ Instituto de Ciencia de Materiales de Sevilla, C.S.I.C.-Universidad de Sevilla, C. Américo Vespucio n49, 41092 Sevilla, Spain.

${ }^{3}$ Departamento de Química Inorgánica, Facultad de Química, Universidad de Sevilla, Sevilla 41071, Spain.

*Prof. Dr. J.M. Valverde

Facultad de Física

Universidad de Sevilla

Avenida Reina Mercedes s/n, 41012 Sevilla (Spain)

Tel +34 954550960 Fax +34954239434

E-mail: jmillan@us.es 


\title{
Large-scale high-temperature solar energy storage using natural minerals
}

\begin{abstract}
The present work is focused on thermochemical energy storage (TCES) in Concentrated Solar Power (CSP) plants by means of the Calcium-Looping (CaL) process using cheap, abundant and non-toxic natural carbonate minerals. CaL conditions for CSP storage involve calcination of $\mathrm{CaCO} 3$ in the solar receiver at relatively low temperature whereas carbonation of $\mathrm{CaO}$ is carried out at high temperature and high $\mathrm{CO} 2$ concentration to use the heat of reaction for power production by means of a $\mathrm{CO} 2$ closed power cycle. Under these conditions, large $\mathrm{CaO}$ particles derived from limestone to be used in industrial processes are rapidly deactivated due to pore plugging, which limits the extent of the reaction. This is favored by the relatively small pores of the $\mathrm{CaO}$ skeleton generated by low temperature calcination, the large thickness of the $\mathrm{CaCO} 3$ layer built upon the $\mathrm{CaO}$ surface and the very fast carbonation kinetics. On the other hand, pore plugging at $\mathrm{CaL}$ conditions for $\mathrm{CSP}$ storage does not limit carbonation of $\mathrm{CaO}$ derived from dolomite (dolime). Dolime is shown to exhibit a high multicycle conversion regardless of particle size, which is explained by the presence of inert $\mathrm{MgO}$ grains that allow the reacting gas to percolate inside the porous particles
\end{abstract}

Keywords: Concentrated Solar Power; Natural carbonates; Multicycle conversion; CaL-CSP storage; $\mathrm{CaL}-\mathrm{CO}_{2}$ capture; particle size. 


\section{Introduction}

It is widely accepted that the massive deployment of power generation from renewable energy sources is one of the essential measures urgently needed to mitigate global warming [1]. Among the different renewable energies, concentrated solar power (CSP) offers the possibility of large scale electricity generation and relatively low cost energy storage in the form of heat for base load power generation. Nowadays, commercial CSP plants are capable of generating power overnight by means of sensible energy storage in molten salts [2-5]. In order to reach a large scale deployment stage, CSP with energy storage needs from cheaper massive energy storage technologies to compete against fossil fuel power plants [6-9]. Thermochemical energy storage (TCES) is being currently investigated as a possible alternative to CSP storage in molten salts. TCES basically consists of using the high temperatures achievable in CSP (up to $\sim 1000^{\circ} \mathrm{C}$ in CSP with tower technology) to carry out an endothermic chemical reaction. The byproducts of the reaction are separately stored and brought together to carry out the reverse exothermic reaction on demand. Main general advantages of TCES systems are the high energy density potentially attainable and the possibility of storing energy in the long term [10-13]. Among diverse alternatives currently under research, the Calcium-Looping $(\mathrm{CaL})$ process based on the calcination/carbonation of $\mathrm{CaCO}_{3}$ offers a great potential as it relies on the use of extremely cheap, widely abundant and non-toxic materials such as natural carbonates [14].

The Calcium-Looping $(\mathrm{CaL})$ process has been widely investigated in the last few years for $\mathrm{CO}_{2}$ capture in coal fired power plants [15]. $\mathrm{CO}_{2}$ capture is performed in this process by the exothermic carbonation reaction of $\mathrm{CaO}$ (Eq.1).

$$
\mathrm{CaO}_{(\mathrm{s})}+\mathrm{CO}_{2(\mathrm{~g})} \rightleftarrows \mathrm{CaCO}_{3(\mathrm{~s})} ; \quad \Delta \mathrm{H}_{\mathrm{r}}^{0}=-178 \mathrm{~kJ} / \mathrm{mol}
$$

The reaction takes place inside a high temperature fluidized bed reactor $\left(\mathrm{T} \sim 650^{\circ} \mathrm{C}\right)$ where the post-combustion flue gas at atmospheric pressure carries a $\mathrm{CO}_{2}$ concentration near $15 \%$ volume. Once $\mathrm{CaO}$ particles are carbonated, they are transported into a second reactor (calciner) where $\mathrm{CaO}$ is regenerated by calcination at high $\mathrm{CO}_{2}$ partial pressure and high 
temperatures $\left(\mathrm{T} \sim 950^{\circ} \mathrm{C}\right)$. This way $\mathrm{CO}_{2}$ at high concentration can be extracted from the calciner to be compressed and stored. The $\mathrm{CaO}$ particles regenerated from calcination are recirculated into the carbonator to be used in a new cycle.

The use of the CaL process in CSP plants for TCES was early proposed in the late 1970s [16-18] and has gained renewed interest in the last years $[11,14,19,20]$. Figure 1 shows an example of integration scheme recently proposed with potentially high global efficiencies $[14$, 21]. The system essentially consists of a power unit, a solar calciner, a carbonator, a $\mathrm{CO}_{2}$ compression-storage system and two reservoirs for both $\mathrm{CaO}$ and $\mathrm{CaCO}_{3}$ storage. The process starts with calcination of $\mathrm{CaCO}_{3}$ particles in a fluidized bed reactor (calciner) using concentrated solar energy as the source of heat. Once calcination occurs, sensible heat of the reaction products $\left(\mathrm{CaO}\right.$ and $\left.\mathrm{CO}_{2}\right)$ is recovered by heat exchangers before storing them separately. Conditions and time of storage can be adapted to energy demand. When needed, $\mathrm{CaO}$ and $\mathrm{CO}_{2}$ are circulated to the carbonator where the heat used for calcination is recovered through the carbonation reaction enthalpy. This heat is carried by the excess $\mathrm{CO}_{2}$ not participating in the carbonation reaction to a gas turbine where electricity is generated in a closed cycle. According to process simulations [14], maximum efficiency CaL conditions for the integration into CSP plants according to this scheme are obtained when carbonation of $\mathrm{CaO}$ takes place at high temperature (above $850^{\circ} \mathrm{C}$ ) and under high $\mathrm{CO}_{2}$ partial pressure. It must be remarked that these $\mathrm{CaL}$ carbonation conditions are radically different from the optimum conditions corresponding to the $\mathrm{CaL}$ process for $\mathrm{CO}_{2}$ capture.

A potential improvement of the CaL-CSP integration consists of using $\mathrm{He}$ in the calciner for reducing the calcination temperature by the enhancement of thermal conductivity of the gas mixture and the great increase of $\mathrm{CO}_{2}$ diffusivity in $\mathrm{He}[22,23]$. The $\mathrm{CO} 2 / \mathrm{He}$ gas mixture exiting the calciner could be separated by selective membranes currently available at commercial scale [24], allowing the storage of $\mathrm{CO}_{2}$ in compression tanks and the recirculation 
of $\mathrm{He}$ to be used in the calciner environment. The use of $\mathrm{He}$ in the calciner allows the calcination reaction to be fully achieved in short residence times at temperatures of just around $700^{\circ} \mathrm{C}$ [21], which would make possible the use of commercial and relatively cheap solar receivers based on metal alloys in the calciner. Despite the high price and limited availability of He, it must be taken into account that this gas would be used in a closed loop. Further technoeconomic analysis should be carried out in future works to assess the effect of possible $\mathrm{He}$ losses and membrane separation inefficiency.

Natural limestone (almost pure $\left.\mathrm{CaCO}_{3}\right)$ is a widely available, low-cost $(<10 \$ /$ ton $)$ and non-toxic $\mathrm{CaO}$ precursor that would help further reducing the cost of the CaL-CSP integration. However, a main potential drawback for the use of natural limestone at industrial scale is the rapid deactivation widely observed in previous works $[25,26]$ under $\mathrm{CO}_{2}$ capture conditions mainly due to agglomeration and sintering of the regenerated $\mathrm{CaO}$ grains, which drastically reduces the surface area available for carbonation in short residence times. The majority of strategies that have been developed to use $\mathrm{CaO}$ based sorbents for $\mathrm{CO}_{2}$ capture involve doping and other expensive treatments, but the compromise between improving the sorbent performance and the final cost of the technology necessarily requires the use of cheap natural carbonates [27]. On the other hand, a recent work has shown that carbonation/calcination conditions in the CaL process for CSP storage process yield a much higher residual conversion for natural limestone and dolomite derived $\mathrm{CaO}$ as compared to $\mathrm{CO}_{2}$ capture conditions [21], which would lead to a high efficiency of the CaL-CSP integration. In the present work, we explore the influence of a further critical parameter on the process performance, which is particle size of these natural carbonates.

Generally, particle size plays a relevant role in industrial processes based on circulating fluidized beds (CFBs) relying on the efficiency of open cyclone exchangers for separation of the particles from the gas streams to transport solids between different reactors [14]. The collection efficiency of commercial cyclones drops dramatically for particles under $\sim 10 \mu \mathrm{m}$ in size [28]. Furthermore, the particles trajectories and residence time in the cyclones depend on their size. 
Thus, the typical particle size lower limit to ensure an acceptable efficiency of cyclones is around $50 \mu \mathrm{m}[29]$.

Most of the investigations focused on the effect of particle size on $\mathrm{CaO}$ conversion during carbonation have been carried out under $\mathrm{CO}_{2}$ capture conditions [30-32]. Under these conditions, the main limitation to carbonation regarding particle size is the diffusion of $\mathrm{CO}_{2}$ molecules through the pores of the $\mathrm{CaO}$ particles. Intraparticle pore diffusion hinders carbonation for particles larger than about $300 \mu \mathrm{m}[33,34]$. Taking into account the limitations imposed by elutriation in commercial cyclones and pore diffusion the optimum particle size used in $\mathrm{CaL}$ pilot scale plants to capture $\mathrm{CO}_{2}$ is in the range 100-300 $\mu \mathrm{m}$ [35-38].

Another important phenomenon that might limit gas-solid reactions concerning particle size is pore-plugging if the pore size is not sufficiently large and carbonation conditions lead to a very fast buildup of a thick $\mathrm{CaCO}_{3}$ product layer on the surface of the $\mathrm{CaO}$ particles. At the harsh calcination conditions used in the $\mathrm{CaL}$ cycle to capture $\mathrm{CO}_{2}$ for sorbent regeneration (high temperatures and high $\mathrm{CO}_{2}$ concentration), the $\mathrm{CaO}$ structure becomes quite sintered with large pores (usually above $\sim 100 \mathrm{~nm}$ ) $[39,40]$ as compared with the thickness of the carbonate layer built up on the surface $(\sim 40-60 \mathrm{~nm})$ [41] during the chemically controlled fast reaction phase. Thus, pore-plugging rarely poses a limitation for carbonation. In the present work, we investigate whether pore plugging might limit carbonation of natural carbonates in the $\mathrm{CaL}$ process at conditions for CSP storage. Under these conditions, calcination is carried out at relatively low temperatures, which would lead to a high porosity $\mathrm{CaO}$ skeleton, whereas carbonation occurs at high temperature under high $\mathrm{CO}_{2}$ concentration leading to the formation of a thick $\mathrm{CaCO}_{3}$ product layer upon the $\mathrm{CaO}$ surface in a chemically controlled and quite fast reaction regime [42]. Thus, it might be foreseen that these conditions favor pore plugging, which would pose a limit to carbonation for particles large enough to be used in CFB reactors.This potentially serious drawback for the practical integration of the CaL process in CSP plants is addressed in this manuscript. 


\section{Experimental}

\subsection{Materials}

The natural carbonate minerals analyzed in our work were: limestone (99.8 wt\% $\mathrm{CaCO}_{3}$ ) from Matagallar quarry in Pedrera (Sevilla, Spain) supplied by Segura S.L., calcitic marble (99.4 wt\% $\mathrm{CaCO}_{3}$ ) from Purchena (Almería, Spain) supplied by Omya Clariana and dolomite (94.4 wt $\% \mathrm{CaMg}\left(\mathrm{CO}_{3}\right)_{2}$ and $5 \mathrm{wt} \% \mathrm{CaCO}_{3}$ ) from Bueres (Asturias, Spain) provided by Dolomitas del Norte (Spain). All the samples were originally supplied in powder form and were sieved (mesh size $45 \mu \mathrm{m}$ ) in order to analyze the multicycle $\mathrm{CaO}$ carbonation behavior for particles of different size range ( $<45$ and $>45 \mu \mathrm{m}$ ) at $\mathrm{CaL}$ conditions for CSP storage. This mesh size has been chosen as a typical low limit to ensure efficient gas-solid separation in commercial cyclones. Particle size upper limit was below $300 \mu \mathrm{m}$ allowing us to dismiss carbonation hindrance by resistance to intraparticle pore diffusion [43].

\subsection{Characterization methods}

Multicycle carbonation/calcination tests were carried out using a Q5000IR thermogravimetric analyzer (TA Instruments) provided with a high sensitivity balance $(<0.1$ $\mu \mathrm{g}$ ) and a furnace heated by IR halogen lamps, which allows for high heating/cooling rates up to $300^{\circ} \mathrm{C} / \mathrm{min}$ and stable isotherms. Under CaL-CSP storage conditions (CaL-CSP test) the experiments started with a precalcination stage from room temperature to the calcination temperature $725^{\circ} \mathrm{C}$, at $300^{\circ} \mathrm{C} / \mathrm{min}$ under helium atmosphere. Then, the temperature was augmented at $300^{\circ} \mathrm{C} / \mathrm{min}$ to $850^{\circ} \mathrm{C}$ to carry out the carbonation stage under a pure $\mathrm{CO}_{2}$ atmosphere during $5 \mathrm{~min}$ followed by a quick decrease of temperature at $300^{\circ} \mathrm{C} / \mathrm{min}$ to $725^{\circ} \mathrm{C}$, which was maintained for $5 \mathrm{~min}$ for $\mathrm{CaO}$ regeneration by changing the gas to pure He. After calcination the temperature was decreased down at $100^{\circ} \mathrm{C} / \mathrm{min}$ to $300^{\circ} \mathrm{C}$ and kept for 2 min in a He atmosphere. This cooling stage aimed at mimicking the extraction of sensible heat from the solids after calcination and before being stored. At this point, pure $\mathrm{CO}_{2}$ atmosphere was 
introduced to repeat the cycle through a carbonation stage. A total of 20 carbonation/calcination cycles were run for each sample. For comparison, multicycle $\mathrm{CO}_{2}$ capture tests were also carried out by employing $\mathrm{CaL}-\mathrm{CO}_{2}$ capture conditions involving carbonation at $650^{\circ} \mathrm{C}$ under a $15 \%$ $\mathrm{CO}_{2} / 85 \%$ air v/v atmosphere and calcination at $950^{\circ} \mathrm{C}$ under high $\mathrm{CO}_{2}$ concentration $(70 \%$ $\mathrm{CO}_{2} / 30 \%$ air v/v) at atmospheric pressure, high cooling/heating rates $\left(300^{\circ} \mathrm{C} / \mathrm{min}\right)$. Short residence times $(5 \mathrm{~min})$ for both calcination and carbonation stages were used as expected in practice. In order to avoid undesired effects due to $\mathrm{CO}_{2}$ diffusion resistance across the sample, small masses $(10 \mathrm{mg})$ was tested in all cases.

Prior to thermogravimetric analyses, both fractions of sieved dolomite were precalcined under $\mathrm{N}_{2}$ at $800^{\circ} \mathrm{C}$ for $30 \mathrm{~min}$ in order to decompose ex-situ $\mathrm{CaMg}\left(\mathrm{CO}_{3}\right)_{2}$ to avoid crepitation phenomena in the TGA apparatus, which is a well-known phenomenon observed especially for relatively large dolomite particles during their decomposition [44]. The ex-situ precalcined samples initially with particles of size $>45 \mu \mathrm{m}$ were checked not to pass across the $45 \mu \mathrm{m}$ mesh size sieve.

Scanning electron micrographs were acquired in a Hitachi S4800 SEM-FEG microscope. Pore size distributions were analyzed by mercury intrusion porosimetry, performed using an Autopore IV instrument (Micromeritics).

\section{Results and Discussion}

Figure 2 shows the thermograms recorded during the first cycles at both $\mathrm{CaL}$ CSP storage and CaL-CO2 capture conditions for marble (similar results are observed for limestone). As can be seen in Fig. 2a, first calcination of marble under He is hindered for the larger particles. This may be explained by the high degree of crystallinity of marble, which hampers $\mathrm{CO} 2$ to diffuse out of the solid during decarbonation as observed in previous works $[45,46]$. In contrast, we observe that calcination is not hindered for dolomite as inert $\mathrm{MgO}$ grains would favor $\mathrm{CO} 2$ diffusion through the solid structure as reported in previous studies 
$[21,47]$. In this regard. In this regard, it would be advantageous to use dolomite instead of natural $\mathrm{CaCO} 3$, which may exhibit hindered calcination in the case of high crystallinity materials such as marble. The use of dolomite would favor calcination at relatively lower temperatures and/or shorter residence times.

Concerning the carbonation stage, Fig. 2 demonstrates a critical role of the carbonation conditions on the kinetics of this stage. As well know from previous studies [16,34], carbonation takes place through two well differentiated phases. A first fast reaction controlled phase occurs on the free surface of $\mathrm{CaO}$ particles, which is followed by a relatively slower diffusion controlled phase characterized by the counter-current diffusion of $\mathrm{CO}_{3}{ }^{2-}$ and $\mathrm{O}^{2-}$ anions across the $\mathrm{CaCO}_{3}$ product layer built up on the $\mathrm{CaO}$ surface $[31,48]$. As seen in Fig. 2a, the fast reaction controlled phase is the main contribution for $\mathrm{CO}_{2}$ uptake under carbonation conditions for CSP storage, which can be explained by the high $\mathrm{CO}_{2}$ concentration and carbonation temperature that enhance the reaction kinetics. In contrast, the fast reaction phase is relatively hindered under carbonation conditions for $\mathrm{CO}_{2}$ capture, which could be explained by the lower $\mathrm{CO}_{2}$ partial pressure (15\% v/v) and lower carbonation temperature but mainly by the harsh calcination conditions for $\mathrm{CaO}$ regeneration, which drastically reduce the $\mathrm{CaO}$ surface area available for carbonation in the fast reaction controlled stage. On the other hand, the slower diffusion phase is promoted under these conditions (Fig. 2b). As reported from process simulations [49] on the integration of the $\mathrm{CaL}$ process for $\mathrm{CO}_{2}$ capture, the $\mathrm{CO}_{2}$ capture efficiency and energy penalty could be improved by prolonging the solids residence time in the carbonator beyond a few minutes due to the relevant role of carbonation in the slower diffusion controlled phase as observed in Fig. 2b. Regarding the integration of the CaL process for CSP storage, our results (Fig. 2a) suggest otherwise. As may be observed in Fig. 2a, carbonation in the slow diffusion controlled phase under CaL-CSP storage conditions is negligible.

In order to quantify the multicycle $\mathrm{CaO}$ conversion performance of the materials employed in our work we will use the effective conversion $X_{e f}$ defined as the ratio of the mass of 
$\mathrm{CaO}$ converted in the carbonation stage of each cycle to the total sample mass before carbonation:

$$
X_{\text {ef } N}=\frac{m_{C a r b N}-m_{N}}{m_{N}} \cdot \frac{W_{C a O}}{W_{C O 2}}
$$

where $m_{N}$ and $m_{\text {Carb } N}$ are the masses of the sample before and after carbonation at the Nthcycle, respectively, and $W_{\mathrm{CaO}}=56 \mathrm{~g} / \mathrm{mol}$ and $W_{\mathrm{CO} 2}=44 \mathrm{~g} / \mathrm{mol}$ are the molecular masses of $\mathrm{CaO}$ and $\mathrm{CO}_{2}$. By using the effective conversion we take into account the possible presence of inert oxides in the material at the $\mathrm{CaL}$ conditions employed, as is the case of $\mathrm{MgO}$ for dolomite, which prevents $X_{e f}$ to reach unity. It thus allows for an objective comparison of the performance of the diverse materials tested regardless of their composition as regards the relevant parameter for CSP, i.e. the energy released per unit mass of material entering the carbonator at the Nth cycle, which is given by $X_{\text {efN }}$ times $\Delta \mathrm{Hr} / W_{C a O}(\mathrm{~kJ} / \mathrm{g})$ where $\Delta \mathrm{H}_{\mathrm{r}}^{0}=-178 \mathrm{~kJ} / \mathrm{mol}$ is the reaction enthalpy.

Data on the multicycle effective conversion under CaL-CSP storage and $\mathrm{CaL}-\mathrm{CO}_{2}$ capture conditions for the sieved natural minerals are shown in Figure 3. Remarkably, a clear difference is observed in the behavior of the different starting carbonates, as well as in the behavior of the different particle size fractions analyzed as depending on the CaL conditions. In the case of CSP storage conditions, the multicycle conversion is severely hindered for both limestone and marble and for particles larger than $45 \mu \mathrm{m}$, reaching a conversion value at the 20th-cycle, $X_{\text {ef 20 }}$, close to 0.16 . However, for particles smaller than $45 \mu \mathrm{m}, \mathrm{X}_{\mathrm{ef} 20}$ is substantially higher for both particle size ranges. On the other hand, there is no effect of particle size on the multicycle conversion of $\mathrm{CaO}$ derived from limestone and marble when tested under $\mathrm{CO}_{2}$ capture conditions (Figure 3b). As seen in previous works [30,31], this small particle size does not pose a limitation under conditions for $\mathrm{CO}_{2}$ capture. 
The much lower conversion values measured under $\mathrm{CaL}-\mathrm{CO}_{2}$ capture conditions (Figure $3 \mathrm{~b}$ ) as compared to CaL-CSP storage conditions are due to the harsh calcination conditions involved in $\mathrm{CO} 2$ capture (high temperature under high $\mathrm{CO}_{2}$ concentration) leading to a severe sintering of the $\mathrm{CaO}$ grains as the number of cycles increases $[15,50]$. As reported elsewhere, we observe that these calcination conditions cause a drastic loss of conversion of the formed $\mathrm{CaO}$ [40].

The influence of the type of $\mathrm{CaL}$ conditions (either for CSP storage or $\mathrm{CO}_{2}$ capture) on the multicycle conversion performance of $\mathrm{CaO}$ as depending on particle size is explainable from the relative thickness of the $\mathrm{CaCO}_{3}$ built upon the $\mathrm{CaO}$ surface, as compared to the size of the pores in the $\mathrm{CaO}$ skeleton, and the carbonation kinetics in the fast reaction controlled stage (Fig. 4). The fast reaction controlled stage ends up when the $\mathrm{CaCO}_{3}$ layer built upon the $\mathrm{CaO}$ exposed surface reaches a critical thickness, which is expected to be around $40-50 \mathrm{~nm}$ at carbonation conditions for $\mathrm{CO}_{2}$ capture $\left(\mathrm{T} \sim 650^{\circ} \mathrm{C}\right.$ and $15 \%$ vol. concentration) [34]. The thickness of this product layer is increased if the carbonation temperature is increased as is the case at $\mathrm{CaL}$ conditions for CSP storage [42]. Under $\mathrm{CaL}-\mathrm{CO}_{2}$ capture conditions, the $\mathrm{CaO}$ structure is severely sintered by the harsh calcination conditions and the typical size of the pores is typically over $100 \mathrm{~nm}$ as measured in our work by mercury intrusion porosimetry (Fig. 4), which is smaller than the thickness of the carbonate layer at the end of the recation controlled stage. Thus, $\mathrm{CO}_{2}$ molecules may diffuse into the pores of the $\mathrm{CaO}$ particles and pore-plugging would not pose a limitation to carbonation in the fast chemically controlled stage. On the other hand, the size of the pores generated in the $\mathrm{CaO}$ skeleton formed by calcination in the absence of $\mathrm{CO}_{2}$ in the calciner environment at relatively low temperatures (as is the case for CSP storage conditions) is typically on the order of tens of nanometers (Fig. 4), whereas the thickness of the $\mathrm{CaCO}_{3}$ layer generated at the high carbonation temperature under high $\mathrm{CO}_{2}$ concentration can be over $100 \mathrm{~nm}$ [42]. Moreover, this carbonate layer is very rapidly formed due to the fast reaction kinetics at the high carbonation temperatures used for CSP storage as seen in Fig. 2. The external surface area of the $\mathrm{CaO}$ grains derived from calcination at CaL-CSP storage 
conditions would thus become quickly plugged, which impedes the access of $\mathrm{CO}_{2}$ to the internal surface area of the $\mathrm{CaO}$ skeleton.

Figure 5 shows SEM micrographs representative of the surface morphology of $\mathrm{CaO}$ derived from limestone and marble after calcination at the 20th-cycle under CaL-CSP storage and $\mathrm{CaL}-\mathrm{CO}_{2}$ capture conditions, respectively. As may be seen, the pores observable for the $\mathrm{CaO}$ particles cycled under CaL-CSP storage conditions show a size on the order of tens of nanometers (Fig. 5a) in contrast with the wider pores $(\sim 100 \mathrm{~nm})$ observable in the highly sintered $\mathrm{CaO}$ particles after being cycled under $\mathrm{CaL}-\mathrm{CO}_{2}$ capture conditions (Fig. 5b).

SEM micrographs shown in Figure 6 illustrate the effect of particle size on the morphology of the $\mathrm{CaO}$ particles derived from $\mathrm{CaCO}_{3}$ and cycled under CaL-CSP storage conditions. As can be observed, the $\mathrm{CaO}$ grains appear more sintered for the starting $\mathrm{CaCO}_{3}$ sample with particles larger than $45 \mu \mathrm{m}$ (Fig. 6a), which is consistent with the pronounced deactivation experienced by this sample. Arguably, the $\mathrm{CaO}$ pores that become plugged by the product layer in the case of the larger particles are prone to sinter in the successive calcinations, which progressively reduce the $\mathrm{CaO}$ surface area available for carbonation. In contrast, the pores of the smaller particles $(<45 \mu \mathrm{m})$ would be fully accessible to the $\mathrm{CO}_{2}$, which leads to carbonation of the whole available $\mathrm{CaO}$ surface. Thus, the thick $\mathrm{CaCO}_{3}$ layer formed by carbonation is regenerated into a relatively porous $\mathrm{CaO}$ skeleton in each calcination stage of the cycles, which would explain the relatively high porosity of these samples observed in the SEM pictures even after 20 cycles (Fig. 6b).

As a rule of thumb, optimum operation of CFB reactors and commercial cyclones to recover the solids from the gas streams requires using particles of size on the order of $100 \mu \mathrm{m}$ [38]. Thus, the limitation posed by particle size (in the range of tens of microns) observed in our work for the natural calcium carbonate mineral under CaL-CSP storage conditions is a potentially relevant issue for the integration of the $\mathrm{CaL}$ process into CSP plants. However, our 
results indicate also that the multicycle behavior of dolomite is totally different from that of the natural calcium carbonates, limestone and marble, described above. Figure $3 \mathrm{c}$ and $\mathrm{d}$ show multicycle effective conversion data for dolomite samples tested under CSP storage and $\mathrm{CO}_{2}$ capture conditions, respectively. As can be seen, the effective conversion of dolomite is rather high despite the presence of $\mathrm{MgO}$ grains inert to carbonation at the $\mathrm{CaL}$ conditions used. As reported in previous works $[45,51]$, these inert grains contribute to stabilizing the $\mathrm{CaO}$ structure by mitigating aggregation and sintering of the $\mathrm{CaO}$ grains. Moreover, in contrast with the behavior of natural $\mathrm{CaCO}_{3}$, particle size (in the range of tens of microns) does not limit carbonation under CaL-CSP storage conditions, as seen from multicycle effective conversion data obtained for particles of size in the different ranges tested (Fig. 3c). It may be thus argued that the presence of inert $\mathrm{MgO}$ grains would help also mitigate pore-plugging. Presumably, $\mathrm{CO}_{2}$ molecules would find a path across the pores between these $\mathrm{MgO}$ grains to percolate inside the particles for carbonating the whole available $\mathrm{CaO}$ surface. SEM micrographs in Fig. 7 reveal a noticeable segregation of the $\mathrm{MgO}$ and $\mathrm{CaO}$ grains that takes place in the dolomite samples tested under CaL-CSP storage conditions (Fig. 7a). These wide $\mathrm{MgO}$ domains could favor the diffusion of $\mathrm{CO}_{2}$ to the interior of the particles, thus allowing for a high multicycle effective conversion even in the case of relatively large particles to be employed in the practical application.

\section{Conclusions}

The present work shows the relevant limitation posed by pore-plugging for the multicycle conversion of $\mathrm{CaO}$ derived from natural $\mathrm{CaCO} 3$ minerals such as limestone and

marble when cycled at $\mathrm{CaL}$ conditions for CSP storage involving carbonation at high temperature/high $\mathrm{CO} 2$ concentration and calcination at low temperature. Pore-plugging causes 
a substantial drop of the multicycle conversion of $\mathrm{CaO}$ derived from these natural calcium carbonate particles larger than about $50 \mu \mathrm{m}$, which should be necessarily employed in the practical application due to technical limitations imposed by the use of CFB reactors and commercial cyclones. On the other hand, it has been seen that pore-plugging is not a limiting mechanism in the case of dolomite arguably due to the presence of inert $\mathrm{MgO}$ domains, which helps the diffusion of $\mathrm{CO} 2$ into the inner pores of the $\mathrm{CaO}$ particles. Moreover, calcination at low temperatures is enhanced for dolomite as compared to natural $\mathrm{CaCO} 3$ minerals, for which calcination can be hindered in the case of high crystallinity samples and relatively large particles. It may be thus concluded that, regarding the multicycle conversion of the material, the use of dolomite would be a more advantageous alternative for the integration of the CaL process into CSP plants.

\section{Acknowledgments}

This work was supported by the Spanish Government Agency Ministerio de Economía y Competitividad and FEDER funds (contracts CTQ2014-52763-C2-1-R and CTQ2014-52763-C2-2-R) and Andalusian Regional Government (Junta de AndaluciaFEDER contract TEP-7858). One of the authors (PESJ) is supported by a Marie CurieJunta de Andalucía Posdoc Talentia grant. The authors also thank VPPI-US for the AP current contract. We gratefully acknowledge the Functional Characterization, XRD and SEM services of the Innovation, Technology and Research Center of the University of Seville (CITIUS). 


\section{References}

[1] S. Chu, A. Majumdar, Opportunities and challenges for a sustainable energy future, Nature, 488 (2012) 294-303.

[2] H.L. Zhang, J. Baeyens, J. Degrève, G. Cacères, Concentrated solar power plants: Review and design methodology, Renewable and Sustainable Energy Reviews, 22 (2013) 466-481.

[3] A.G. Fernández, S. Ushak, H. Galleguillos, F.J. Pérez, Development of new molten salts with $\mathrm{LiNO}_{3}$ and $\mathrm{Ca}\left(\mathrm{NO}_{3}\right)_{2}$ for energy storage in CSP plants, Applied Energy, 119 (2014) 131140.

[4] L. Sang, M. Cai, Y. Zhao, N. Ren, Y. Wu, C. Burda, Mixed metal carbonates/hydroxides for concentrating solar power analyzed with DSC and XRD, Solar Energy Materials and Solar Cells, 140 (2015) 167-173.

[5] Y.-t. Wu, Y. Li, N. Ren, C.-f. Ma, Improving the thermal properties of $\mathrm{NaNO}_{3}-\mathrm{KNO}_{3}$ for concentrating solar power by adding additives, Solar Energy Materials and Solar Cells, 160 (2017) 263-268.

[6] D. Barlev, R. Vidu, P. Stroeve, Innovation in concentrated solar power, Solar Energy Materials and Solar Cells, 95 (2011) 2703-2725.

[7] V. Siva Reddy, S.C. Kaushik, K.R. Ranjan, S.K. Tyagi, State-of-the-art of solar thermal power plants-A review, Renewable and Sustainable Energy Reviews, 27 (2013) 258-273.

[8] S. Kuravi, J. Trahan, D.Y. Goswami, M.M. Rahman, E.K. Stefanakos, Thermal energy storage technologies and systems for concentrating solar power plants, Progress in Energy and Combustion Science, 39 (2013) 285-319.

[9] Y. Jemmal, N. Zari, M. Maaroufi, Thermophysical and chemical analysis of gneiss rock as low cost candidate material for thermal energy storage in concentrated solar power plants, Solar Energy Materials and Solar Cells, 157 (2016) 377-382.

[10] K.E. N'Tsoukpoe, H. Liu, N. Le Pierrès, L. Luo, A review on long-term sorption solar energy storage, Renewable and Sustainable Energy Reviews, 13 (2009) 2385-2396.

[11] P. Pardo, A. Deydier, Z. Anxionnaz-Minvielle, S. Rougé, M. Cabassud, P. Cognet, A review on high temperature thermochemical heat energy storage, Renewable and Sustainable Energy Reviews, 32 (2014) 591-610.

[12] H.Ö. Paksoy, Thermal energy storage for sustainable energy consumption: fundamentals, case studies and design, Springer Netherlands, 2007.

[13] T.M.I. Mahlia, T.J. Saktisahdan, A. Jannifar, M.H. Hasan, H.S.C. Matseelar, A review of available methods and development on energy storage; Technology update, Renewable and Sustainable Energy Reviews, 33 (2014) 532-545.

[14] R. Chacartegui, A. Alovisio, C. Ortiz, J.M. Valverde, V. Verda, J.A. Becerra, Thermochemical energy storage of concentrated solar power by integration of the calcium looping process and a $\mathrm{CO}_{2}$ power cycle, Applied Energy, 173 (2016) 589-605.

[15] J. Blamey, E.J. Anthony, J. Wang, P.S. Fennell, The calcium looping cycle for large-scale $\mathrm{CO}_{2}$ capture, Progress in Energy and Combustion Science, 36 (2010) 260-279.

[16] R. Barker, The reversibility of the reaction $\mathrm{CaCO}_{3} \rightleftarrows \mathrm{CaO}+\mathrm{CO}_{2}$, Journal of Applied Chemistry and Biotechnology, 23 (1973) 733-742.

[17] R. Barker, The reactivity of calcium oxide towards carbon dioxide and its use for energy storage, Journal of Applied Chemistry and Biotechnology, 24 (1974) 221-227.

[18] G. Flamant, D. Hernandez, C. Bonet, J.-P. Traverse, Experimental aspects of the thermochemical conversion of solar energy; Decarbonation of $\mathrm{CaCO}_{3}$, Solar Energy, 24 (1980) 385-395.

[19] J. Cot-Gores, A. Castell, L.F. Cabeza, Thermochemical energy storage and conversion: Astate-of-the-art review of the experimental research under practical conditions, Renewable and Sustainable Energy Reviews, 16 (2012) 5207-5224. 
[20] R. Chacartegui, et al. Sistema de almacenamiento de energía termoquímica a partir fuente térmica a media temperatura basado en la integración de ciclo calcinación-carbonatación (Calcium Looping) y ciclo cerrado de potencia de $\mathrm{CO}_{2}$. Patent P201500493.

[21] B. Sarrion, J.M. Valverde, A. Perejon, L. Perez-Maqueda, P.E. Sanchez-Jimenez, On the multicycle activity of natural limestone/dolomite for thermochemical energy storage of concentrated solar power, Energy Technology, 4 (2016) 1013-1019.

[22] E.E. Berger, Effect of steam on the decomposition of limestone 1,1, Industrial \& Engineering Chemistry, 19 (1927) 594-596.

[23] E.L. Cussler, Diffusion: Mass Transfer in Fluid Systems, Cambridge University Press, 1997.

[24] E. Taketomo, M. Fujiura, Porous materials for concentration and separation of hydrogen or helium, and process therewith for the separation of the gas, in, Google Patents, 1984.

[25] B.R. Stanmore, P. Gilot, Review-calcination and carbonation of limestone during thermal cycling for $\mathrm{CO}_{2}$ sequestration, Fuel Processing Technology, 86 (2005) 1707-1743.

[26] P. Sun, J.R. Grace, C.J. Lim, E.J. Anthony, The effect of $\mathrm{CaO}$ sintering on cyclic $\mathrm{CO}_{2}$ capture in energy systems, AIChE Journal, 53 (2007) 2432-2442.

[27] M. Erans, V. Manovic, E.J. Anthony, Calcium looping sorbents for $\mathrm{CO}_{2}$ capture, Applied Energy, 180 (2016) 722-742.

[28] B. Zhao, Y. Su, J. Zhang, Simulation of gas flow pattern and separation efficiency in cyclone with conventional single and spiral double inlet configuration, Chemical Engineering Research and Design, 84 (2006) 1158-1165.

[29] R. Utikar, N. Darmawan, M. Tade, Q. Li, G. Evans, M. Glenny, V. Pareek, Hydrodynamic Simulation of Cyclone Separators, 2010.

[30] J.C. Abanades, D. Alvarez, Conversion limits in the reaction of $\mathrm{CO}_{2}$ with lime, Energy and Fuels, 17 (2003) 308-315.

[31] S.K. Bhatia, D.D. Perlmutter, Effect of the product layer on the kinetics of the $\mathrm{CO}_{2}$-lime reaction, AIChE Journal, 29 (1983) 79-86.

[32] Y. Li, C. Zhao, H. Chen, Y. Liu, Enhancement of Ca-based sorbent multicyclic behavior in Ca looping process for $\mathrm{CO}_{2}$ separation, Chemical Engineering \& Technology, 32 (2009) 548555.

[33] G.S. Grasa, J.C. Abanades, M. Alonso, B. González, Reactivity of highly cycled particles of $\mathrm{CaO}$ in a carbonation/calcination loop, Chemical Engineering Journal, 137 (2008) 561-567.

[34] G. Grasa, R. Murillo, M. Alonso, J.C. Abanades, Application of the random pore model to the carbonation cyclic reaction, AIChE Journal, 55 (2009) 1246-1255.

[35] H. Dieter, C. Hawthorne, M. Zieba, G. Scheffknecht, Progress in Calcium Looping post combustion $\mathrm{CO}_{2}$ capture: Successful pilot scale demonstration, Energy Procedia, 37 (2013) 4856.

[36] B. Arias, M.E. Diego, J.C. Abanades, M. Lorenzo, L. Diaz, D. Martínez, J. Alvarez, A. Sánchez-Biezma, Demonstration of steady state $\mathrm{CO}_{2}$ capture in a $1.7 \mathrm{MWth}$ calcium looping pilot, International Journal of Greenhouse Gas Control, 18 (2013) 237-245.

[37] J. Ströhle, M. Junk, J. Kremer, A. Galloy, B. Epple, Carbonate looping experiments in a 1 MWth pilot plant and model validation, Fuel, 127 (2014) 13-22.

[38] D.P. Hanak, E.J. Anthony, V. Manovic, A review of developments in pilot-plant testing and modelling of calcium looping process for $\mathrm{CO}_{2}$ capture from power generation systems, Energy \& Environmental Science, 8 (2015) 2199-2249.

[39] D. Alvarez, J.C. Abanades, Pore-Size and Shape Effects on the Recarbonation Performance of Calcium Oxide Submitted to Repeated Calcination/Recarbonation Cycles, Energy \& Fuels, 19 (2005) 270-278.

[40] J.M. Valverde, P.E. Sanchez-Jimenez, L.A. Perez-Maqueda, Limestone calcination nearby equilibrium: Kinetics, $\mathrm{CaO}$ crystal structure, sintering and reactivity, The Journal of Physical Chemistry C, 119 (2015) 1623-1641.

[41] D. Alvarez, J. Carlos Abanades, Determination of the critical product layer thickness in the reaction of $\mathrm{CaO}$ with $\mathrm{CO}_{2}$, Industrial and Engineering Chemistry Research, 44 (2005) 56085615. 
[42] Z.S. Li, F. Fang, X.Y. Tang, N.S. Cai, Effect of temperature on the carbonation reaction of $\mathrm{CaO}$ with $\mathrm{CO}_{2}$, Energy \& Fuels, 26 (2012) 2473-2482.

[43] F. García-Labiano, A. Abad, L.F. de Diego, P. Gayán, J. Adánez, Calcination of calciumbased sorbents at pressure in a broad range of $\mathrm{CO}_{2}$ concentrations, Chemical Engineering Science, 57 (2002) 2381-2393.

[44] J.M. Valverde, P.E. Sanchez-Jimenez, L.A. Perez-Maqueda, Ca-looping for postcombustion $\mathrm{CO}_{2}$ capture: A comparative analysis on the performances of dolomite and limestone, Applied Energy, 138 (2015) 202-215.

[45] A. de la Calle Martos, J.M. Valverde, P.E. Sanchez-Jimenez, A. Perejon, C. GarciaGarrido, L.A. Perez-Maqueda, Effect of dolomite decomposition under $\mathrm{CO}_{2}$ on its multicycle $\mathrm{CO}_{2}$ capture behaviour under calcium looping conditions, Physical Chemistry Chemical Physics, 18 (2016) 16325-16336.

[46] P.E. Sanchez-Jimenez, J.M. Valverde, A. Perejón, A. de la Calle, S. Medina, L.A. PérezMaqueda, Influence of ball milling on $\mathrm{CaO}$ crystal growth during limestone and dolomite calcination: Effect on $\mathrm{CO}_{2}$ capture at Calcium Looping conditions, Crystal Growth \& Design, (2016). In Press: DOI: 10.1021/acs.cgd.6b01228

[47] J.M. Valverde, A. Perejon, S. Medina, L.A. Perez-Maqueda, Thermal decomposition of dolomite under $\mathrm{CO}_{2}$ : Insights from TGA and in situ XRD analysis, Physical Chemistry Chemical Physics, 17 (2015) 30162-30176.

[48] Z. Sun, S. Luo, P. Qi, L.-S. Fan, Ionic diffusion through Calcite $\left(\mathrm{CaCO}_{3}\right)$ layer during the reaction of $\mathrm{CaO}$ and $\mathrm{CO}_{2}$, Chemical Engineering Science, 81 (2012) 164-168.

[49] C. Ortiz, R. Chacartegui, J.M. Valverde, J.A. Becerra, L.A. Perez-Maqueda, A new model of the carbonator reactor in the calcium looping technology for post-combustion $\mathrm{CO}_{2}$ capture, Fuel, 160 (2015) 328-338.

[50] V. Manovic, J.-P. Charland, J. Blamey, P.S. Fennell, D.Y. Lu, E.J. Anthony, Influence of calcination conditions on carrying capacity of $\mathrm{CaO}$-based sorbent in $\mathrm{CO}_{2}$ looping cycles, Fuel, 88 (2009) 1893-1900.

[51] A. Perejón, J. Miranda-Pizarro, L.A. Pérez-Maqueda, J.M. Valverde, On the relevant role of solids residence time on their $\mathrm{CO}_{2}$ capture performance in the Calcium Looping technology, Energy, 113 (2016) 160-171. 


\section{Figures}

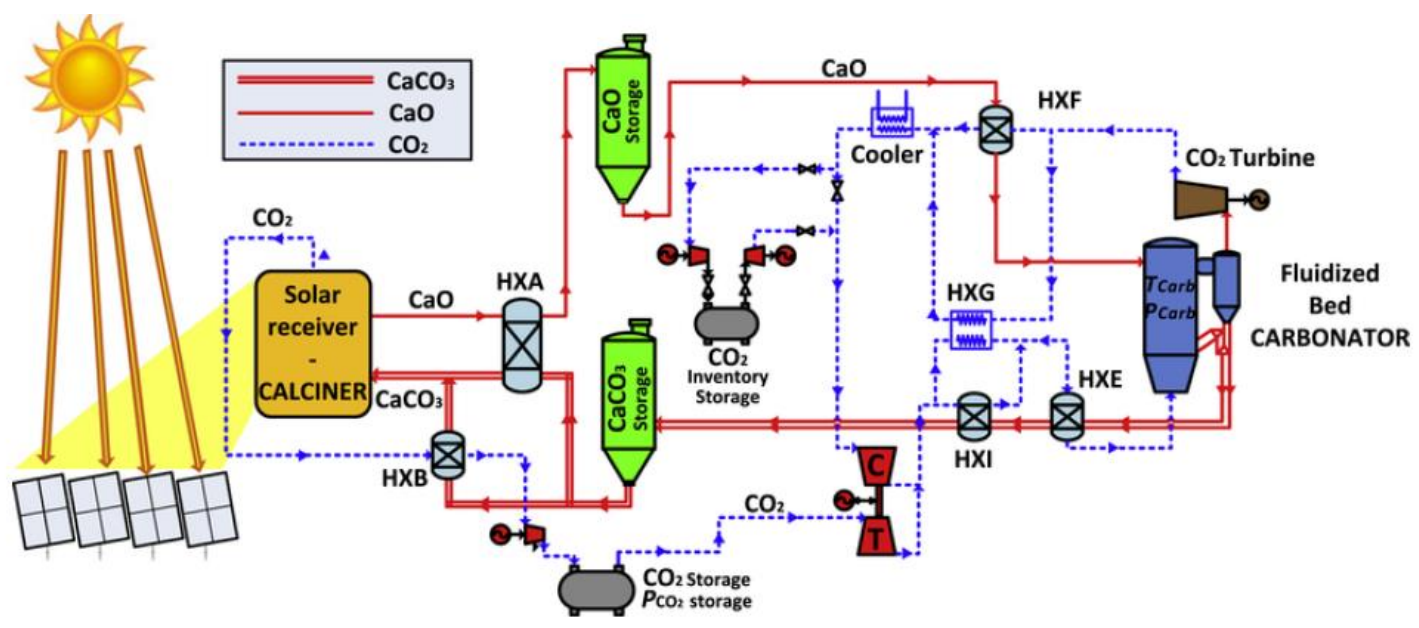

Fig. 1. Calcium-Looping thermochemical energy storage system for concentrated solar power plants. The integration scheme is developed in Ref. [14], where the interested reader may find additional details. 

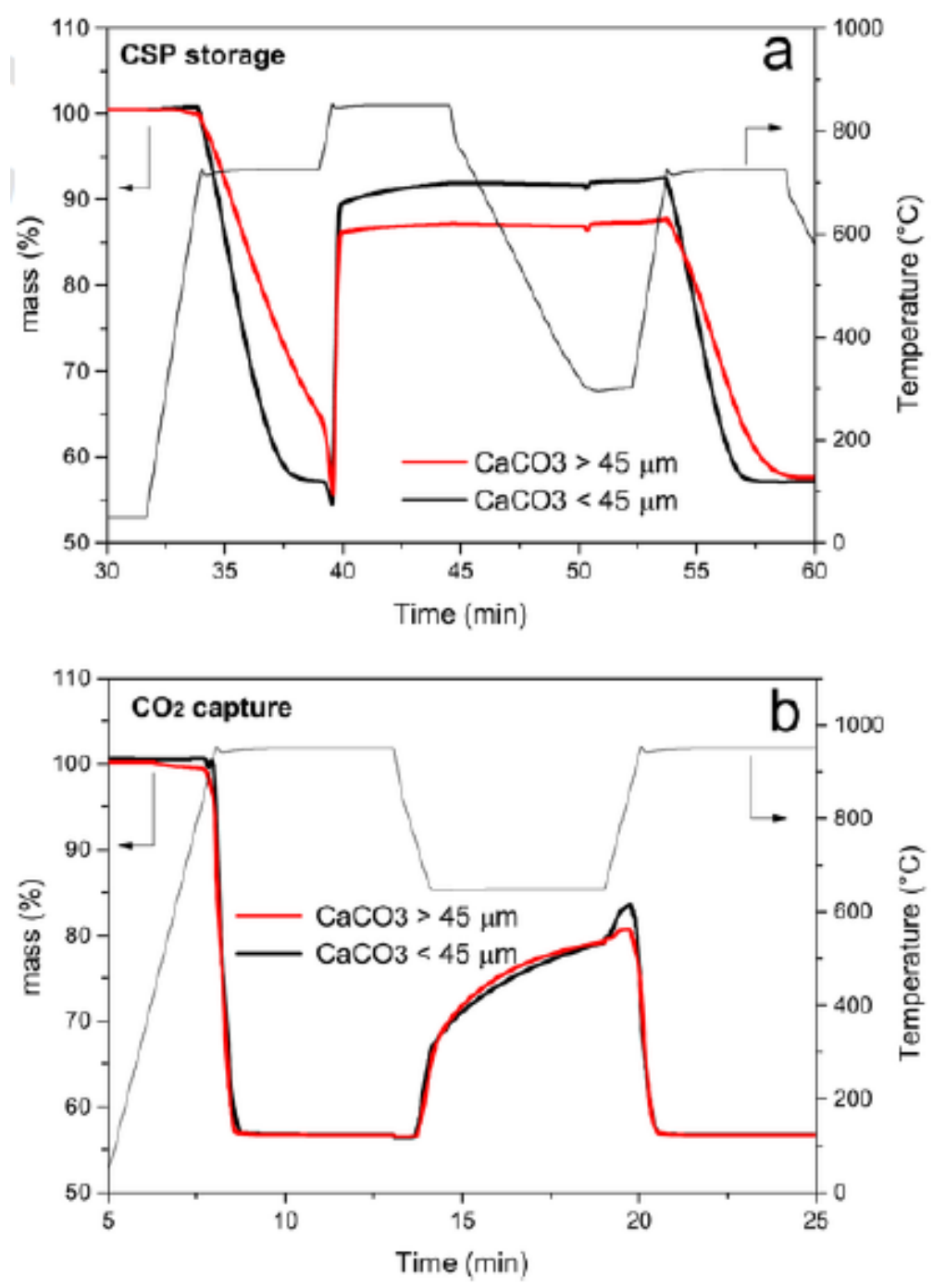

Fig. 2. Time evolution of temperature and sample weight for the first carbonation cycle of $\mathrm{CaCO} 3$ using different particles sizes, under CaL-CSP storage (a) and CaL-CO2 capture conditions (b), as indicated. 

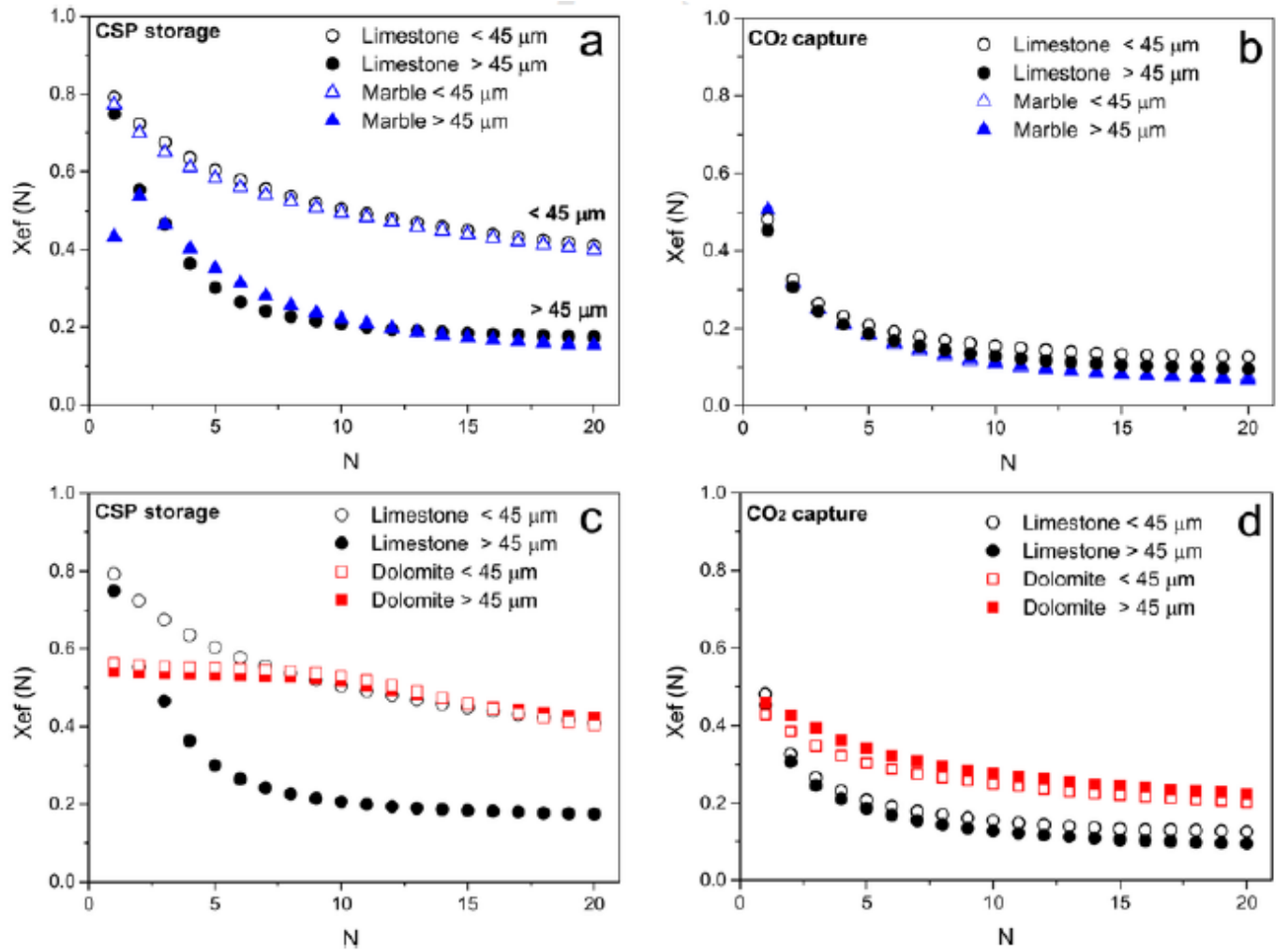

Fig. 3. Multicycle effective conversion (Xef) of sieved limestone and marble samples subjected to CaL cycles under CaL-CSP storage (a) and CaL-CO2 capture conditions (b), and sieved dolomite compared to limestone under CaL-CSP (c) and CaL-CO2 capture conditions (d).

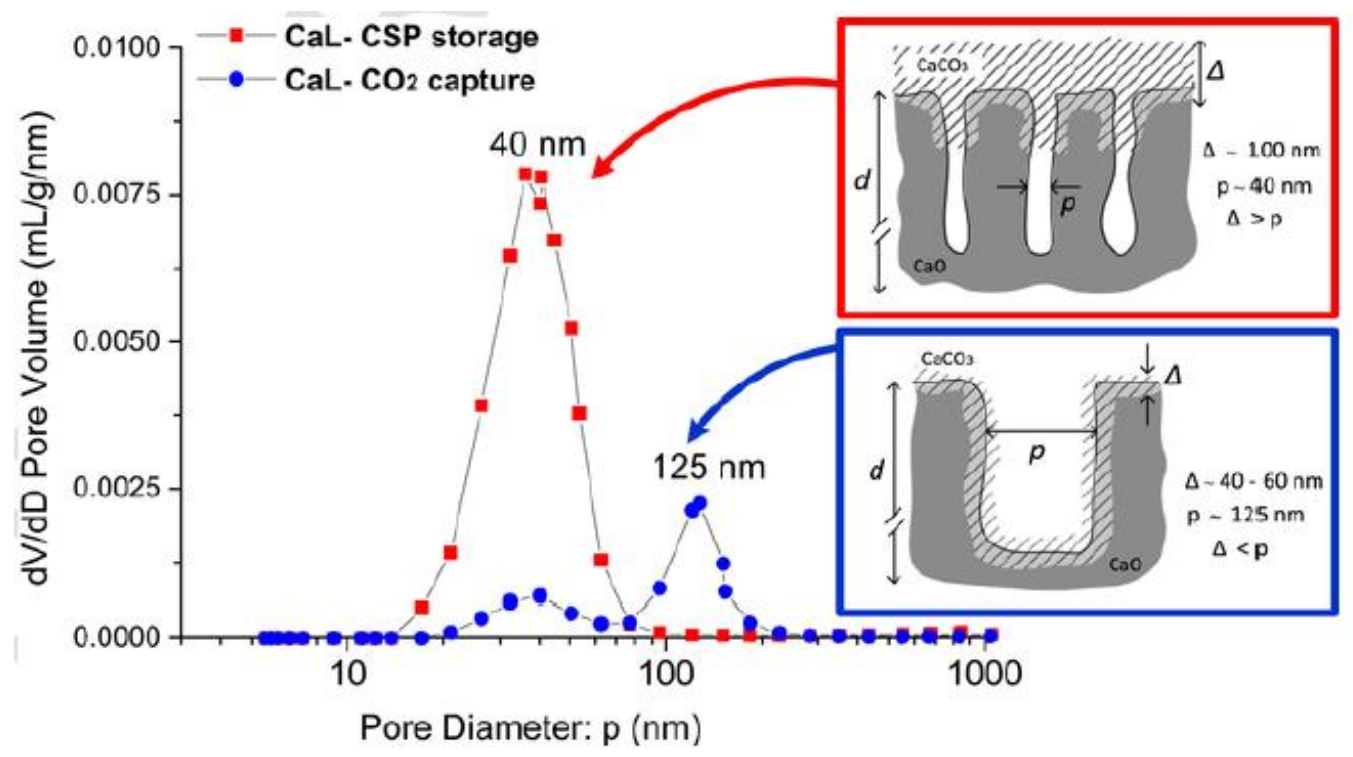

Fig. 4. Pore size distribution measured by $\mathrm{Hg}$ intrusion porosimetry of $\mathrm{CaO}$ obtained after calcination under pure $\mathrm{N} 2$ at $750{ }^{\circ} \mathrm{C}$ and pure $\mathrm{CO} 2$ at $950{ }^{\circ} \mathrm{C}$ corresponding to CSP storage and $\mathrm{CO} 2$ capture conditions, respectively. The insets show the growing process of a $\mathrm{CaCO} 3$ layer on a porous $\mathrm{CaO}$ particle under CaL-CSP storage and CaL-CO2 capture conditions leading to pore-plugging for relatively large $\mathrm{CaO}$ particles under CSP conditions. 

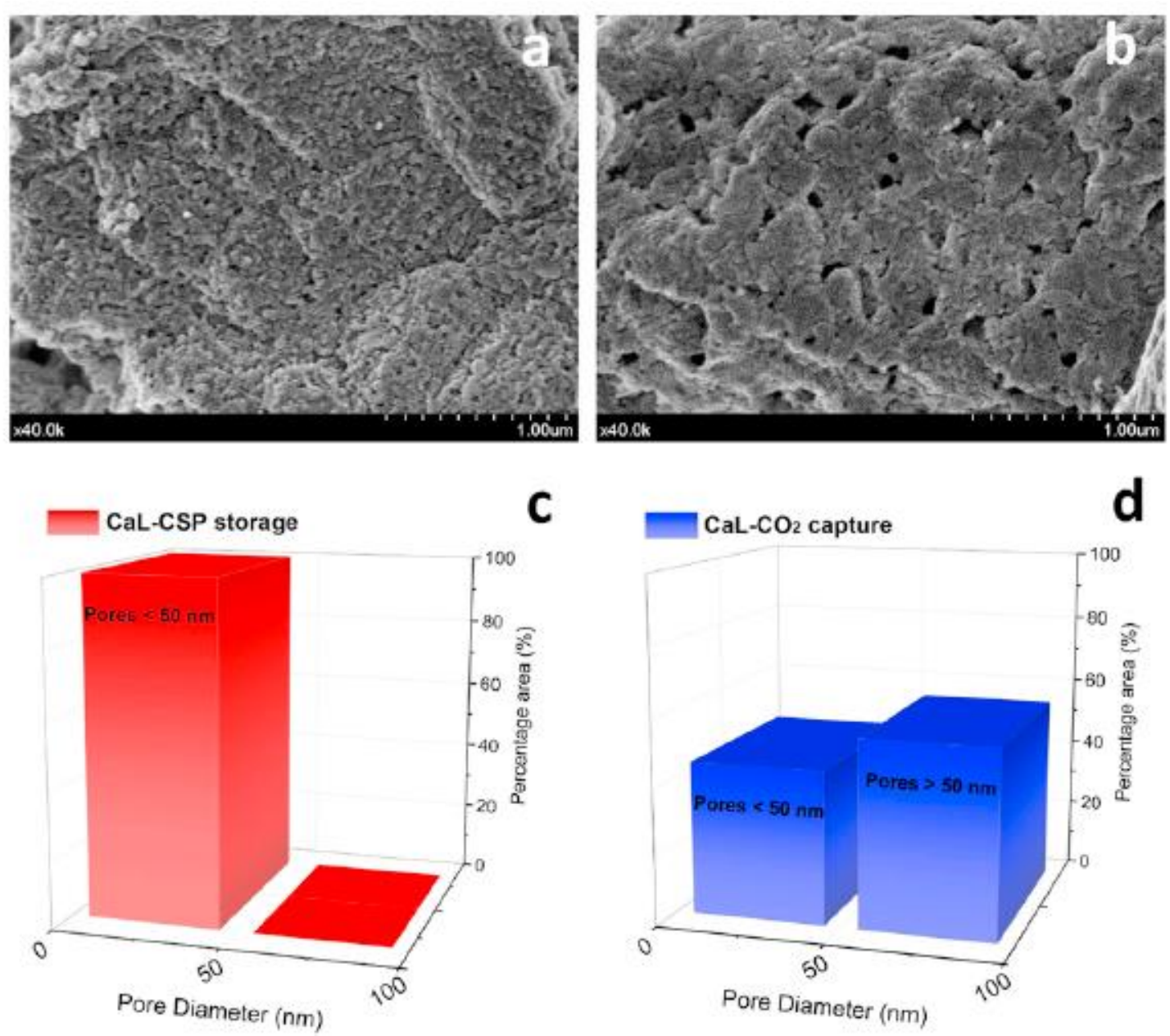

Fig. 5. SEM micrographs of $\mathrm{CaO}$ sorbents, derived for natural $\mathrm{CaCO} 3(<45 \mu \mathrm{m})$ subjected to $\mathrm{CaL}$ cycles after calcination at the 20th-cycle under CaL-CSP storage (a) and CaL-CO2 capture (b) conditions, and the corresponding pore size distributions obtained from image analysis $(c, d)$. 

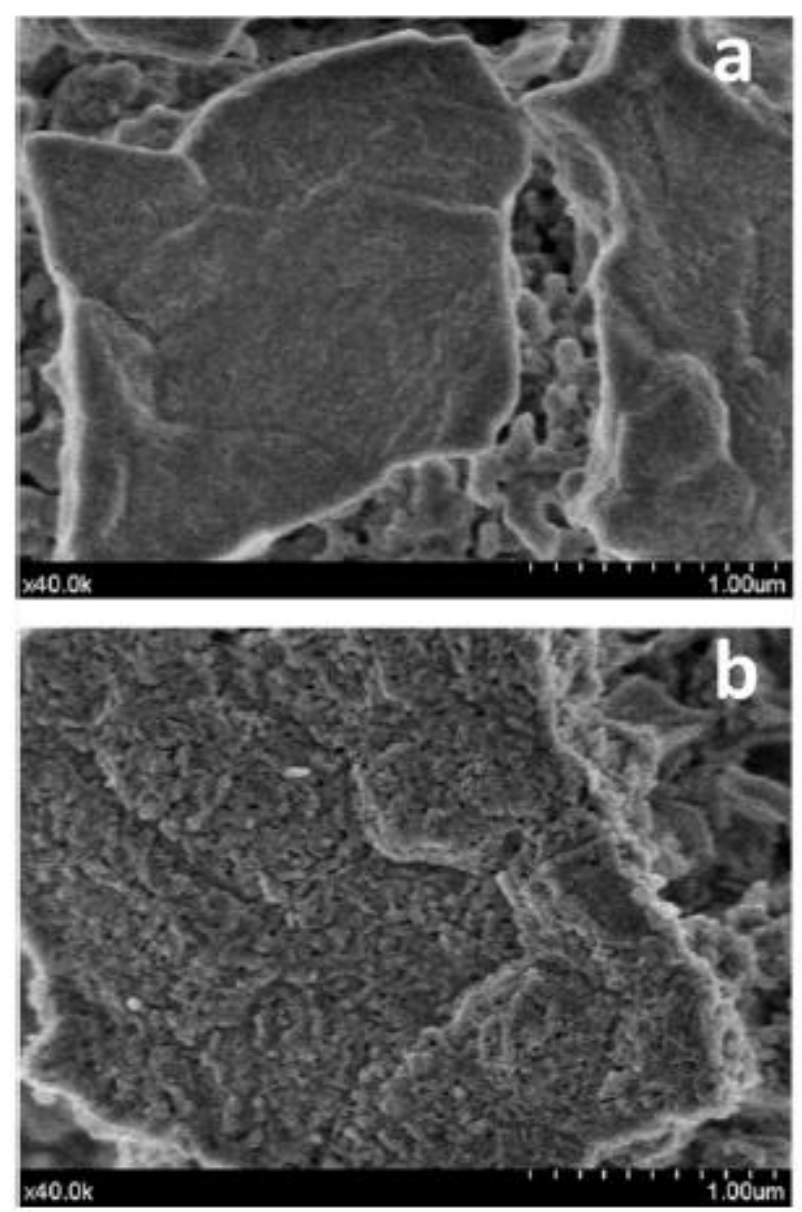

Fig. 6. SEM micrographs obtained for natural $\mathrm{CaCO} 3$ particles subjected to $\mathrm{CaL}$ cycles after calcination at the 20th-cycle under CaL-CSP storage conditions: (a) $>45 \mu \mathrm{m}$; (b) $<45 \mu \mathrm{m}$. 

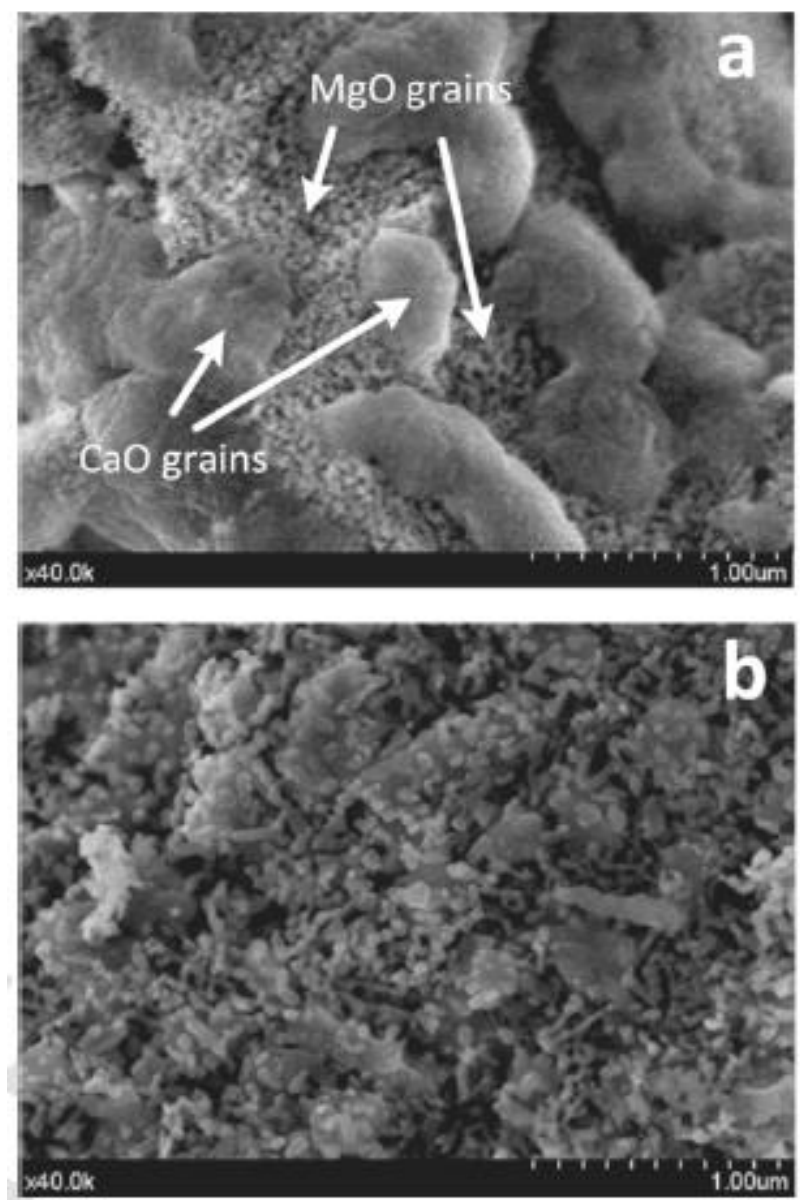

Fig. 7. SEM micrographs obtained for dolomite $(<45 \mu \mathrm{m})$ subjected to CaL cycles after calcination at the 20th-cycle under CaL-CSP storage (a) and CaL-CO2 capture (b) conditions. 